\title{
FINDING THEIR PLACE IN THE WORLD: USING DIGITAL STORYTELLING TO UNDERSTAND THE INTERSECTIONS BETWEEN STUDENTS TECHNOLOGY USE AND THEIR WORK, LIFE, PLAY AND LEARNING
}

\author{
Peter Bryant, University of Sydney, Australia
}

\begin{abstract}
Understanding how and with your students participate in learning and how technology and social media supports that learning is a key challenge for modern higher education institutions. Learning practices intersect personal, professional and educational lives in complex, inter-connected and personally defined and managed ways. Drawing on the analysis of digital stories told by 100 students at the University of Sydney Business School, this paper will explore the unique methodological approaches of digital storytelling and student-led research to understanding how technology shapes and intersects the learning experience. It will also identify how students use technology (and especially extended forms of social media) to forms connections between their work, life, play and learning.
\end{abstract}

\section{The challenge of understanding the student experience}

How universities use information and data from students to ascertain and improve their experiences is central to most modern higher education institutional and policy frameworks on teaching and learning (Neary, 2016). Depending on the country where the University is located, this data is collected centrally by government authorities (the National Student Survey in the United Kingdom, for example) or at significant points during the student journey (near completion of a unit of study in the case of many student institution-level satisfaction surveys). Much of this data collection is directly related to the teaching activity within a degree program or specific course or unit. The collection of this data is also controversial and divisive in both the literature and in many institutions, in part as it is often used as an academic staff performance management instrument or contribute to the metricisation of education through global ranking tables or government mandated measures like the Teaching Excellence Framework in the UK (Berbegal-Mirabent, Mas-Machuca, \& Marimon, 2018).

Student satisfaction surveys specifically can also profligate and sometimes reward reactive decision making by both the academics under scrutiny, the wider institutional management and the government setting the policy agenda (Klemenčič \& Chirikov, 2015). Measuring student satisfaction in this way often focuses on the lowest scores and poorest performances 
and does not provide insights into how to scale and sustain exceptional performance (Burgess, Senior, \& Moores, 2018). The information collected by these instruments locates the student in the abstract (to support the necessity of ensuring student anonymity in many cases). The student experience is reduced to measurable and comparable numbers on scales and simple free text associations related only to the delivery of unit at a single point in time (Aldemir \& Gülcan, 2004). The student's story and how those experiences are related other learning experiences in different units or their holistic experience of being at University can get lost. The challenge that student satisfaction surveys fail to address is how do we as institutions understand the collective experience of higher education. How do our students engage in learning and teaching, free from the influence of attainment and success in a specific unit taken at snapshot moments?

\section{Defining student learning}

How and why our students participate in learning represents a critical challenge for higher education institutions. Learning is not bound by the seats and lecterns of the lecture theatre or the user experience of the Learning Management System. It is more than the combination of series of assessment tasks, consumed content and didactic instruction. Learning practices intersect personal, professional and educational lives in complex, inter-connected and personally defined and managed ways. Learning inhabits conversations, reflections, casual and fleeting connections, ambitions and expectations that are not always located in the classroom or even on campus. The ways in which university students engage in the activity of learning outside of the "classroom" are part determined by how curriculum, assessment and teaching (and the teacher) shape the kinds of social learning practices needed by or enforced on students to successfully complete a unit of study or programme (Huda et al., 2017; Lai, 2015). How students engage in learning has further evolved within the socially constructed environment of social media, exposing intersections between learning and the rest of a student's life and challenging and defining notions of expertise, authority, informality, expediency, immediacy and representation (Ellis \& Goodyear, 2016; Greenhow \& Lewin, 2016). Learning practices intersect personal, professional and educational lives in complex, inter-connected and personally defined and managed ways affording students the opportunity to make and share identity and to tell the stories of their lives to who they choose (Clark \& Rossiter, 2008). Learning inhabits conversations, reflections, casual and fleeting connections, ambitions and expectations that are not always located in the classroom or even on campus (Fried \& Harper, 2017; Hare, 2018). The use of technology and social media and the practices that emerge from them is at the nexus of these connections, creating personal ecosystems of engagement and relationships. Students, when engaging in learning through and with their technology and social media presence are challenging and reshaping the sources of authentic and credible knowledge through the messiness of social media mediated practices (McLoughlin \& Lee, 2008). This is both as creators and makers of knowledge themselves (through social media making, remixing and repurposing (bricolage and found) and sharing for example) and as aggregators of expertise or credibility from within their own 
Finding their Place in the World: Using Digital Storytelling to Understand the Intersections between Students Technology Use and their Work, Life, Play and Learning

Peter Bryant

peer networks or more fleeting and searchable links to networked knowledge residing on-line (Bridgstock, 2016; Hamid, Waycott, Kurnia, \& Chang, 2015).

\section{Digital storytelling as model of engaging with students and their learning}

The University of Sydney Business School (USBS) is a faculty of the University of Sydney, Australia and is one of the leading Business Schools in the Asia-Pacific region. It has over 16000 students, across a range of undergraduate and postgraduate programs. It delivers specialisations in areas such as Accounting and Finance, Management, Human Resources and emerging areas such as Big Data, International Business and Supply Chain Management. The scope and scale of the educational offering have made community development challenging at the School. Students are distributed across a large and sprawling campus, in fractured groups and classes that do not afford many opportunities to connect and build strong links with a cohort. With student experience surveys focusing on specific classes, the capacity to explore and understand the holistic student experience was critical. We needed to expose the impacts of technology, the ways in which students interacted with each other and the engagement they sought and made with the School and the community. Building on the model of student conversations that had been piloted at the London School of Economics since 2015 (Bryant, 2017; Liote \& Axe, 2016), the Work. Live. Play. Learn project (WLPL) was started in 2018 to provide an opportunity for students to tell their story and have that shared with colleagues, academics and the wider community. The heart of the project was the recording of conversations with one hundred USBS students over a one-month period in situ around the campus. These conversations were led by a former student (working as a research assistant) and three current students of the School, giving the project an ethnography-like feel, with students from within the community leading the storytelling. The conversations were conducted with individuals or small groups of students and were recorded on video to make the artefacts shareable and lasting. The use of video and high-quality audio changed the dynamic of the conversation, with students knowing that the words they used, and their images would be shared. The result was fifty-five stories featuring one hundred students from across all our programs and over forty-one hours of video.

This application of digital storytelling methodology represented a form of social pedagogy, where interaction, engagement and learning emerged from the telling of asynchronous and sometimes disconnected stories shared widely with participants and the wider community (Benmayor, 2008; Stewart, 2017). Sociality and social constructivism informed how other students located themselves in the institutional community, both through the consumption of the stories of other students but more importantly, through the telling of them to others (Yang \& Wu, 2012). These stories represented encounters between students that may never have happened without the intervention of the project. The use of digital stories provided an opportunity to share human insights into learning, a concept often blurred by the metrics of satisfaction and outcomes (Robin, 2016; Stewart \& Ivala, 2017). This project created fleeting 
encounters between students and their stories, which we hoped would provide insights to both themselves and the institution to make education better.

Using the same small group of student researchers and using thematic and content analysis, the conversations were interpreted to expose the lived authentic experiences of our students and show the connections and linkages between their experiences and uses of technology. It was also critical that students who shared their stories were not seen as data or in the abstract, but as active and identifiable members of the community, and that their insights would be used to better their (and others) learning experiences. Four key questions informed both the digital storytelling aspect of the project and the ensuing analysis:

- What are our students lived and authentic experiences of learning?

- How do our students react/respond to the requirements placed upon by us?

- How do they balance the intersections and tensions of work, life and play on learning?

- What role does technology and social media play in all this?

\section{Authentic experiences and the role of technology}

The core principle of WLPL was to explore and understand how students lived and authentic experiences of learning and locate those stories within the fuzzy boundaries of what it means to study at USBS. Whilst the School has structured the student experience within the traditional mechanisms of qualifications, majors, specialisations and requirements, learning for our students was described in their stories as a far more complex process. Achieving a degree, passing a unit or completing an assessment placed pressures and expectations on our students, ranging from time and deadlines, to group engagement and problem solving through to competing priorities channelled into single unitary windows of submission or performance. For many students, studying with the School was a multi-year commitment, rent with uncertainty and change; moving homes or countries, finding themselves in new and unfamiliar places, having to study, learn and live adult lives. There was not a single or common purpose or motivation amongst our students for coming to University, or what they wanted to achieve at the end of it. There were no common sets of skills or knowledge that informed practices or behaviours or prepared them for the pressures of living their lives. Expectations of the kinds of support, structures or pastoral care that the University could provide were contested, sometimes contradictory and critical. The types of activity (such as assessment) they were undertaking as students were in equal parts scaffolded and underprepared for. The student's stories revealed varying states of transition, with the impacts of uncertainty, development, growth and reflection often starkly (and critically) described. These states of transition effected how they engaged with their learning and how they interacted with other students, academics and their discipline. Technology played a critical part in shaping and coping with the transition, acting as a both a catalyst for change and the balancing force between two uncertain states. The analysis identified three examples of these transient and uncertain states, aligned with dichotomous perspectives on social engagement and interaction, use of technology, teaching and learning, work and career and 
identity as a person and professional. What emerged were complex, intersecting narratives describing personal pathways through their work, life, play and learning. Whilst our students shared the experience of being in transition, there were significant differences in how they got here, how they coped with being in transition and how they planned their way out into more defined and stable places. There were also substantive differences in what role they saw for themselves, technology and social media, their academics and the institution in supporting, facilitating or challenging their transition.

\section{Alone/Together}

Social interaction, engagement and connections were at the core of many of our student's stories, both in the context of learning and teaching, but equally in how they understood their university experience:

"You talk to people in class and stuff, and that's all right. But in between classes, especially if you have long breaks, you don't really know who to talk to. You don't really know where to go. I remember my first semester, just wandering around, not really knowing what to do."

As their university experience progressed our students acquired new skills, different sets of connections and engagements with people and learn from their experiences. Students were pragmatic about the importance of a social network; some so that they could engage with others, others to do group work and share and for others, the opportunity to discuss thorny or challenging issues or problems in order to find the best or most strategic solutions:

"One thing I want after completing my degree is to be able to work independently. And by this, I meant not by myself. But just being able to know what to do in situations that maybe I wouldn't be able to handle, before I came to university. And just knowing how to approach different situations with - what kind of strategies to use and things."

Social media was an interesting lens through which transition was observed. One student deleted many of their social media accounts when they moved from their home country to Australia, as social media reminded them of all the social contacts and networks they were missing out on. Even though they shared their sense of isolation and loneliness in their story, being connected on social media amplified those feelings rather than abrogating them.

\section{Life/Job}

This was an interesting example of the state of transition being described by our students. One of the common conceptions of higher education is that it is designed to deliver job-ready graduates with an agile set of skills as defined (and required) by industry. Whilst many of the students discussed the type of job or career they anticipated having after they graduate, there was significant uncertainty about where their degree would take them. Even though a Business degree by its nature is both generalist and specific, many of the students talked about 
how the degree would help them live their lives, achieve their hopes and dreams or achieve ambitions that were not specifically related to that important "first job":

"Well, I think by doing a commerce degree here, I do want to try and be my own - you know, like an entrepreneur. Create my own business. I mean, that being said, it is quite far into the future. So I'm not entirely sure just yet. But I like to think I can get, given the skills that allow me to pursue that path, should I want to."

Many of the students described how the degree will make them more mobile, support portfolio careers, facilitate travel and international experiences. Running counter to the notions of job-ready graduates, these students wanted to use their university experiences and technology to be life ready, developing skills that were transferable across contexts and industries:

\begin{abstract}
"I think, personally, I want to go and see the world first. And with my degree I feel like I don't want to go through a straight-line career path through business, move up the ladder. I want to do something creative, maybe join a start-up business, maybe do something along those lines. But not necessarily heavy numbers, heavy bookkeeping, heavy work like that."
\end{abstract}

Finally, the importance of networks and connections was a prominent theme in many stories. Students were critical of the value of friend or click aggregation on sites like LinkedIn, instead valuing networks that supported their career or life ambitions and supported the development of lasting connections:

"I'm (not) like, oh, hey, I added X amount of people on LinkedIn or made X amount of friends. It was more just a different way of viewing where I can see myself long term in both my professional career and personal life as well. Because sometimes at uni, you're kind of stuck in your own little bubble."

\title{
Teaching/Learning
}

Teaching and learning represented very visible lenses through which to explore transition. The exploration of a student's personal learning journey, with its requisite set of choices and decisions about which teaching and learning resources and activities to access and prioritise was another way in which transition was described. Not necessarily located within solely reflective frames, personal learning choices represented pragmatic decisions often made in relation to the pressures of work, life and play on learning, but also made based on the skills and knowledge they believed they needed for success:

"To be honest, I don't think it's (online recording of lectures) helpful to me personally because it's a different interaction when you come to lectures and when you watch them online. Even when I'm trying to retain the information, I feel like I retain better information when I go to the face-to-face lectures 
Finding their Place in the World: Using Digital Storytelling to Understand the Intersections between Students Technology Use and their Work, Life, Play and Learning

Peter Bryant

rather than online lectures. Because it's so easy to get distracted when you're online and you have all of these tabs open and everything."

\title{
Conclusions
}

Writers such as Palmer, O'Kane, and Owens (2009) have described the first-year student experience transition as a betwixt state, where students are in-between spaces without feeling like legitimate members of the University community. Rooted in the imperative to succeed that permeates modern higher education, transition has become a byword for facilitating that success and minimising attrition (and maximising attainment). As Baker and Stirling (2016) note:

\begin{abstract}
“'Transition' has become a powerful discourse around the processes of change that are negotiated as students move between different educational spaces (in the cases described here, school and university), which involve many aspects of the individual's experience (physical, social, cultural, economic, emotional, educational, disciplinary, professional.” (Baker \& Stirling, 2016; pp.46-47)
\end{abstract}

The stories told by our students describe their transition within complex constructs of their experiences at our School. They told of their issues with sociality, with integration, with identify, with direction and ambition and with expectation. These were not simply rooted in the classroom or the way they are assessed. Their experiences at our School are technological, cultural, social, economic, disciplinary and pragmatic. But it was equally evident that each of these experiences was part of the journey of the student through their betwixt states, building confidence, leveraging their technology and social media presences and identifying insights and advice for the students to come after them. It is, in the truest definition of liminality, a rite of passage between pre-liminal and post-liminal states that create community in part generated by a shared uncertainty about the journey and destination (Turner, 1977; 1987).

Our students' digital stories described their location within a variety of liminal spaces (personal, professional, cultural, technological and educational) that intersected their common expectations of engaging in higher education. It was clear that for some of our students being in these liminal spaces was disruptive and uncomfortable. It was also clear through the that for the students in the early stages of their experience at the School, the skills required to build and develop connections that might bind them together with other people in similar liminal transition states were nascent. Many of the students told us how they relied on the School to provide the fertile contexts to meet people, develop and understand the connections between places, authorities and knowledge. It was through this that our students learnt how to build and maintain connections and friends, how to break and adjust them when necessary, and where to apply the technology they owned or we provided them with (group work was a good example of this) and ultimately find commonality and difference and form lasting bonds. But equally they rarely relied on us to provide the ways and platforms through which they forged and maintained those connections. 
Students with more experience of education and the School demonstrated clearly in their stories a desire to help other students with their transition or to provide them with ways to benefit from their experiences. It was one of the unintended outcomes of this project. The digital storytelling methodology provided a lasting artefact to students that they could use to make their experiences and insights widely shared with emerging colleagues and networks. It could be argued that it was both the experiences of making these broader spans of connections between work, life, play and learning, and the opportunity to reflect and share them that contributed towards their progressions towards a more certain, less transitional post liminal state. Learning in both its transdisciplinary form, as well as the more specific discipline level learning is a part of their transition. The student experience literature can sometimes privilege more traditional first year experience activities such as orientation, clubs and societies, icebreakers and other pre-disciplinary exposures as critical to determining the student experience (often as measured in student experience/satisfaction surveys). From our stories, learning and teaching played an equally critical role in forming and maintaining connections and helping clarify identity, ambition and intention.

This was not a universal experience in our classes or learning experiences. There is significant opportunity to build on how these impactful experiences could help us to better define assessment, shape the kinds of examples or cases we use in class, provide better career development opportunities and interventions, how we plan Welcome Week and Open Day activities and how we better use the human and disciplinary capital extant within our lectures, tutorials, seminars, research outputs and online spaces to minimise dissonance and provide the capabilities for students to move through transitory states. Our learning and teaching can provide the opportunity test connections, experiment with pathways in and through knowledge and skills and the capacity to learn from the uncertainty and liminality. There is no benefit to our students in assuming we can eliminate all the uncertainty before they arrive. But we can create the environment that affords the opportunity to learn through liminality and transition.

\section{References}

Aldemir, C., \& Gülcan, Y. (2004). Student satisfaction in higher education. Higher education management and policy, 16(2), 109-122.

Baker, S., \& Stirling, E. (2016). Liminal Spaces, Resources and Networks: Facebook as a Shaping Force for Students' Transitions into Higher Education. Learning and Teaching: The International Journal of Higher Education in the Social Sciences, 9(2), 42-65.

Benmayor, R. (2008). Digital storytelling as a signature pedagogy for the new humanities. Arts and Humanities in Higher Education, 7(2), 188-204.

Berbegal-Mirabent, J., Mas-Machuca, M., \& Marimon, F. (2018). Is research mediating the relationship between teaching experience and student satisfaction? Studies in Higher Education, 43(6), 973-988. 
Finding their Place in the World: Using Digital Storytelling to Understand the Intersections between Students Technology Use and their Work, Life, Play and Learning

Peter Bryant

Bridgstock, R. (2016). Educating for digital futures: what the learning strategies of digital media professionals can teach higher education. Innovations in education and teaching international, 53(3), 306-315.

Bryant, P. (2017). It doesn't matter what is in their hands: understanding how students use technology to support, enhance, and expand their learning in a complex world. Paper presented at the Proceedings of the $5^{\text {th }}$ International Conference on Educational Technologies (ICEduTech 2017), Sydney, Australia.

Burgess, A., Senior, C., \& Moores, E. (2018). A 10-year case study on the changing determinants of university student satisfaction in the UK. PloS one, 13(2), e0192976.

Clark, M. C., \& Rossiter, M. (2008). Narrative learning in adulthood. New directions for adult and continuing education, 2008(119), 61-70.

Ellis, R. A., \& Goodyear, P. (2016). Models of learning space: integrating research on space, place and learning in higher education. Review of Education, 4(2), 149-191. doi:10.1002/rev3.3056

Fried, J., \& Harper, R. (2017). Learning Everywhere on Campus: Teaching Strategies for Student Affairs Professionals. Routledge.

Greenhow, C., \& Lewin, C. (2016). Social media and education: reconceptualizing the boundaries of formal and informal learning. Learning, Media and Technology, 41(1), 6-30.

Hamid, S., Waycott, J., Kurnia, S., \& Chang, S. (2015). Understanding students' perceptions of the benefits of online social networking use for teaching and learning. The Internet and Higher Education, 26, 1-9.

Hare, R. (2018, May 2). The importance of weak ties. Hare of the Blog [Blog post]. Retrieved from https://rosiehare.com/2018/05/02/the-importance-of-weak-ties/\#more-89

Huda, M., Sabani, N., Shahrill, M., Jasmi, K. A., Basiron, B., \& Mustari, M. I. (2017). Empowering Learning Culture as Student Identity Construction in Higher Education. Student Culture and Identity in Higher Education (pp. 160-179). IGI Global.

Klemenčič, M., \& Chirikov, I. (2015). How do we know how students experience higher education? On the use of student surveys. The European Higher Education Area (pp. 361379). Springer.

Lai, C. (2015). Modeling teachers' influence on learners' self-directed use of technology for language learning outside the classroom. Computers \& Education, 82, 74-83.

Liote, L., \& Axe, H. (2016). LSE 2020: Capturing the Student Voice On the Future of Educational Technology. Retrieved from http://ti.lse.ac.uk/wpcontent/uploads/2016/08/LSE2020visionReport-FINAL.pdf

McLoughlin, C., \& Lee, M. J. (2008). The three p's of pedagogy for the networked society: Personalization, participation, and productivity. International Journal of Teaching and Learning in Higher Education, 20(1), 10-27. 
Neary, M. (2016). Teaching Excellence Framework: a critical response and an alternative future. Journal of Contemporary European Research, 12(3).

Palmer, M., O’Kane, P., \& Owens, M. (2009). Betwixt spaces: student accounts of turning point experiences in the first-year transition. Studies in Higher Education, 34(1), 37-54. doi:10.1080/03075070802601929

Robin, B. R. (2016). The power of digital storytelling to support teaching and learning. Digital Education Review, 30, 17-29.

Stewart, K. D. (2017). Classrooms as 'safe houses'? The ethical and emotional implications of digital storytelling in a university writing classroom. Critical Studies in Teaching and Learning, 5(1), 85-102.

Stewart, K. D., \& Ivala, E. (2017). Silence, voice, and “other languages”: Digital storytelling as a site for resistance and restoration in a South African higher education classroom. British Journal of Educational Technology, 48(5), 1164-1175.

Turner, V. (1977). Variations on a Theme of Liminality. In S. F. Moore \& B. Myerhoff (Eds.), Secular Ritual (pp. 36-52). Amsterdam, NL: Van Gorcum.

Turner, V. (1987). Betwixt and between: The liminal period in rites of passage. In L. C. Mahdi, S. Foster, \& M. Little (Eds.), Betwixt and Between: Patterns of masculine and feminine initiation (pp. 3-19). La Salle, IL: Open Court.

Yang, Y.-T. C., \& Wu, W.-C. I. (2012). Digital storytelling for enhancing student academic achievement, critical thinking, and learning motivation: A year-long experimental study. Computers \& Education, 59(2), 339-352. 